\title{
Wet and Dry Deposition Flux Measurements of Atmospheric Microplastic Particles in Central Germany
}

Sarmite Kernchen ( $\nabla$ Sarmite.Kernchen@uni-bayreuth.de)

University of Bayreuth

Holger Schmalz

University of Bayreuth

Martin G. J. Löder

University of Bayreuth

Christoph Georgi

Technische Universität Berlin

Andrej Einhorn

University of Bayreuth

Andreas Greiner

University of Bayreuth

Anke C. Nölscher

University of Bayreuth

Christian Laforsch

University of Bayreuth

Andreas Held

Technische Universität Berlin

\section{Research Article}

Keywords: plastic pollution, dry and wet deposition of microplastics, $\mu \mathrm{FTIR}$, Raman spectroscopy

Posted Date: February 17th, 2022

DOI: https://doi.org/10.21203/rs.3.rs-1355961/v1

License: (c) (i) This work is licensed under a Creative Commons Attribution 4.0 International License.

Read Full License 


\section{Abstract}

Air emissions, atmospheric transport and subsequent deposition of microplastics to other environments are now recognized. However, atmospheric dry and wet deposition of plastic particles and how different weather conditions may affect this fallout process are still poorly investigated. Hence, we examined wet and dry deposition of airborne plastic particulates from the atmosphere at a site in Kassel in Central Germany. Monthly samples of wet and dry deposition were taken separately over one year (05/2019$05 / 2020$ ) and analysed by micro-Fourier-Transform Infrared spectroscopy ( $\mu \mathrm{FTIR}$ ) down to $11 \mu \mathrm{m}$. Additionally, one exemplary dry deposition sample was subjected to Raman analyses to investigate the abundance of dry deposited plastic particles in the lower micron and submicron size range. Microplastic particles in size range of $11 \mu \mathrm{m}$ to $130 \mu \mathrm{m}$ were detected in all wet deposition samples and in 5 out of 12 dry deposition samples by $\mu$ FTIR. Polypropylene particles were found most frequently and accounted for $62 \%$ and $54 \%$ of all particles in wet and dry deposition, respectively. Wet deposition of plastics dominated at the study site and comprised $62 \%$ of the total number and $70 \%$ of the total mass of deposition. Plastic wet deposition fluxes (DFs) were $10 \pm 5 \mathrm{MPs} \mathrm{m}^{-2}$ day $^{-1}$ and accounted for $4284 \mathrm{MPs} \mathrm{m}^{-2} \mathrm{a}^{-1}$. Microplastic deposition was elevated when the dominant wind direction was recorded in the direction from the city centre of Kassel and concentrations in precipitation correlated significantly with populationweighted air mass trajectories. Thus, anthropogenic activities contribute to the MP pollution at the study site. Raman analyses revealed additional plastic particles in the micron $(>10 \mu \mathrm{m})$ and lower micron (between $10 \mu \mathrm{m}$ and $1 \mu \mathrm{m}$ ) range but submicron $(<1 \mu \mathrm{m})$ range particles made of common synthetic polymer materials could not be detected in the exemplary analysed dry deposition sample. Our results suggest that microplastic analysis by $\mu \mathrm{FTIR}$ down to $11 \mu \mathrm{m}$ may underestimate DFs at least by an order of magnitude. However, more comprehensive studies on submicroplastics and nanoplastics $(<100 \mathrm{~nm})$ are needed to fully assess air pollution by plastic particles.

\section{Introduction}

Air pollution is one of the biggest threats to human health, causing millions of deaths worldwide every year [1]. Recently, small plastic particles were determined as a new airborne anthropogenic pollutant, whose accumulation in the atmosphere and deposition can now be expected all over the globe [2-5]. Studies show a variation over several orders of magnitude of airborne microplastic (MP) concentrations and deposition fluxes (DFs). MP concentrations range from $0.01 \mathrm{~m}^{-3}$ in the remote marine atmosphere[6] to $2502 \mathrm{~m}^{-3}$ in urban road-side London (UK) [7] and DFs between $36 \pm 7 \mathrm{~m}^{-2}$ day $^{-1}$ in Dongguan city (China) [8] to $771 \pm 167 \mathrm{~m}^{-2}$ day $^{-1}$ in central London (UK) [9]. Further, the atmosphere can significantly contribute to the plastic pollution of aquatic and terrestrial habitats through airborne transport over long distances up to several thousands of kilometres far from their sources $[6,10]$. Suspended in the air MPs may have direct radiative effects that influence Earth's climate by absorbing and scattering radiation. These effects were assessed as minor but with a tendency to increase if the plastic production and waste management practices will remain unchanged [11]. MP deposited into marine waters, soils, or plants can cause substantial damage and stress to the environment and human health due to their uptake and 
accumulation in food chains [12]. Direct effects are also suspected, as microplastics can enter the human body through the respiratory tract. Studies in the German Weser River catchment, revealed that a human may breath in on average 500 MP particles per day[13] which is probably underestimated since only particles down to $4 \mu \mathrm{m}$ were analysed. In addition to this, tests on human alveolar cells showed that airborne polystyrene microplastics may have toxicologic consequences on human health [14]. Despite these public concerns, atmospheric microplastics are relatively sparsely studied.

Atmospheric deposition of particulate matter by dry and wet deposition is an essential self-cleansing mechanism of the atmosphere [15]. Gravitational settling, vertical turbulent motion, and surface conditions determine particle dry uptake at the Earth's surface (water, soil, vegetation, or buildings), whereas wet deposition processes refer to in-cloud and below-cloud scavenging, i.e., the uptake of pollutants into hydrometeors such as cloud and rain droplets, snowflakes, or hail [16], and transport to the surface. The relative importance of wet versus dry MP deposition depends on the frequency of precipitation. In regions of limited precipitation, the relative importance of MP dry deposition is expected to increase. While dry conditions can significantly extend the MP atmospheric residence time, wet deposition will reduce it. Observational data of dry and wet DFs of MPs are required as input for simulating the MP deposition in global chemical transport and climate models.

So far, only a few studies have addressed these issues of the impact of meteorology on MP deposition [17-22]. Dris et al. (2017) and Allen et al. (2019) showed that rain and snowfall play a significant role in MP scavenging from the atmosphere [18], resulting in a 5-fold increase in fibre deposition during rain events [17]. Precipitation intensity was shown to contribute to MP deposition variability by up to two orders of magnitude [19]. The wet-only deposition was estimated to capture $\sim 70 \%$ of the bulk nthropogenic microfiber deposition in coastal areas around Ireland [20]. In contrast, more than $75 \%$ of the plastic ass was removed from the atmosphere by dry deposition in US-protected areas [21]. Recently, Abbasi et al. (2021) suggested that MP deposition in a semi-arid region of Iran was dominated by dry deposition, while precipitation appeared to washout and inhibit local resuspension of MPs by dampening the ground [22]. The sparse knowledge on atmospheric dry and wet deposition of microplastics and how different weather conditions affect this process reinforces the need for more research on these aspects.

Hence, to advance our understanding of MP pollution in the atmosphere, and to fill the gap of knowledge regarding the impact of meteorological conditions and seasonal changes of MP wet and dry deposition, we studied the temporal variation in MP deposition fluxes and evaluated the relative efficiency of MP (> $11 \mu \mathrm{m})$ dry and wet removal mechanisms in Central Germany. Specifically, the following objectives were pursued: (i) to collect monthly wet and dry deposition samples over the time-period of one year (05/201905/2020); (ii) to count and to determine the type, shape, size, and the colour of the plastic particles by micro-Fourier-Transform Infrared spectroscopy ( $\mu \mathrm{FTIR}$ ) down to $11 \mu \mathrm{m}$ in size; (iii) to investigate the relationships between MP DFs/MP concentrations in precipitation and meteorological parameters, the local wind fields, and population-weighted air mass back trajectories. 
In addition to this, one exemplary dry deposition sample was studied by Raman spectroscopy (iv) to detect MP particles smaller than $11 \mu \mathrm{m}$ (i.e., below the detection limit of $\mu \mathrm{FTIR}$ ).

\section{Methods}

\section{Sampling site}

The study site (latitude $51.32476{ }^{\circ} \mathrm{N}$, longitude $9.52471^{\circ} \mathrm{E}$ ) was located in Central Germany on the premises of a wastewater treatment plant of KASSELWASSER 3 km NE of the city centre of Kassel, and at a distance of $100 \mathrm{~m}$ from the river Fulda. Kassel had a population of 202'137 in 2019 and a population density of $1^{\prime} 900$ people $\mathrm{km}^{-2}$. The average temperature during the sampling period was $13.2^{\circ} \mathrm{C}$, with a total precipitation of $606 \mathrm{~L} \mathrm{~m}^{-2}$. Meteorological data for the sample collection period were retrieved from the wastewater treatment plant Kasse/Wasser and the nearest weather station Kassel-Mitte (Hessisches Landesamt für Naturschutz, Umwelt und Geologie).

The annual precipitation amount was equally distributed over the seasons with a small excess in the winter months. The lowest monthly precipitation sum was $7 \mathrm{~L} \mathrm{~m}^{-2}$ in March 2020, the highest monthly precipitation sum was $127 \mathrm{~L} \mathrm{~m}^{-2}$ in February 2020. The measured rainfall intensity ranged from 0.28 to $0.88 \mathrm{~mm} \mathrm{~h}^{-1}$. Samples were collected under two dominant wind direction conditions, NE and SSW, respectively. The average wind speed over the sampling period was $1.9 \pm 0.4 \mathrm{~m} \mathrm{~s}^{-1}$ corresponding to a light breeze and calm periods (see Supplementary Information Fig. S1 for details of daily precipitation during the sampling period and Table S1 for other meteorological parameters).

\section{Collection of dry and wet atmospheric deposition}

Wet and dry atmospheric deposition samples were collected for intervals of calendar months, over one year starting in May 2019, and ending in May 2020. For sample collection, a custom-made automatic collector with two separate units was built and installed at the sampling site in Kassel (see Supplementary information, Fig. S2). The wet deposition sample collection unit consisted of a collection funnel, a stainless-steel filtration device (Whatman MV050 series, $500 \mathrm{~mL}$, appropriate for filter diameters of $47 / 50 \mathrm{~mm}$ ) and a stainless-steel lid. Controlled by a rain sensor (Kemo M152, 12V, Germany), the collection funnel was opened during rain or snow, and the lid closed during dry periods. Wet deposition samples were in-situ filtered through pre-cleaned stainless-steel filters $(\varnothing=47 \mathrm{~mm}$, pore size $10 \mu \mathrm{m}$, Wolftechnik Filtersysteme GmbH \& Co, Germany), which were changed monthly. Dry deposition samples were collected on pre-cleaned circular stainless-steel plates (custom-made at University of Bayreuth (UBT), $\varnothing=104 \mathrm{~mm} \times 1 \mathrm{~mm}$ ) which were placed on a stainless-steel filter holder (custom-made, similar to Sartorius type SM16260, appropriate for a filter with $\varnothing=100 \mathrm{~mm}$ ). The dry deposition unit was covered with a stainless-steel cap $(150 \mathrm{~mm} \times 70 \mathrm{~mm})$ so that it was sheltered from rain from above, but horizontal wind drafts could carry particles through the $23 \mathrm{~mm}$ slit on the side of the sampler between the filter holder and the lid. 
In total, 8 monthly wet deposition samples were collected from May 2019 to December 2019 and 12 monthly dry deposition samples from May 2019 to April 2020 (cf. Supplementary information, Table S1). The collection of wet deposition samples from January to April 2020 had to be cancelled due to the breakdown of the sensor-triggered lid. Both filters for collection of wet and dry deposition were changed on the same days. The average collection time was 30 days. Three wet deposition and three dry deposition blank samples were taken in the same manner as field samples omitting the collection step. After collection, the stainless-steel filters and plates were placed in pre-cleaned Petri dishes, wrapped in aluminium foil and stored in a refrigerator until they were brought to the laboratory for further processing.

\section{Contamination control}

To prevent contamination, the samples were handled under a laminar flow box whenever possible (Laminar Flow Box FBS, Spetec GmbH). Furthermore, the laboratory was equipped with an air purifier (DustBox with HEPA H14 filter, Möcklinghoff Lufttechnik GmbH) to reduce air-borne contamination. Special care was taken to keep all the units and solutions which came into contact with the sample clean from detectable plastic particles. All reagents and rinsing solutions were filtered through a $0.2 \mu \mathrm{m}$ membrane filter ( $47 \mathrm{~mm}$, cellulose acetate, Whatman, Japan) before use. All glassware, sampling funnels, tweezers, stainless-steel filters, sieves, thermometers, Petri dishes, and all components of the vacuum filtration devices were thoroughly rinsed with pre-filtered MilliQ water, followed by rinsing with pre-filtered $35 \%$ ethanol, and repeatedly washed with pre-filtered MilliQ water. All pre-cleaned units were stored covered with non-plastic lids or wrapped in aluminium foil to minimize contamination from lab air. Stainless-steel filters were placed in the ultrasound bath and sonicated for 15 min before a standardized rinsing process. Reagents and solutions were stored either in glass bottles or in stainless-steel or Teflon spray bottles. The use of plastic tools, containers, and other lab equipment was avoided. The lab is equipped exclusively for MP analyses and no external tasks are allowed. The sample processing procedures were done in a laminar flow box. Cotton lab coats were always worn during the procedures to prevent any contamination of synthetic fibres from clothing. Four out of six wet and dry deposition field blanks were free from MP and the remaining blanks contained individual polystyrene particles. Only one dry deposition sample and two wet deposition samples contained polystyrene particles similar in size to the MP fraction in the blank samples, which were subtracted from field samples.

\section{Sample pre-treatment}

Particles in wet deposition samples which were in-situ filtered on stainless-steel filters (see Methods section) and Petri dishes were rinsed thoroughly in separate glass beaker with pre-filtered water. The particles were re-filtered through the same stainless-steel filter using stainless-steel filtration device (Sartorius 16828, filter holder with $3 \times 500 \mathrm{~mL}$ manifolds) and halved using split pliers (custom-made at UBT, suitable for filters $\varnothing=47 \mathrm{~mm}$, enables half the particulate load on the filter to be washed away). The rinsed particles were resuspended on one to four Anodisc filter(s) (pore size $0.2 \mathrm{~mm}, \varnothing=25 \mathrm{~mm}$, Anodisc25, Whatman, Germany) depending on particle load using a custom-made (UBT) filtration device 
consisting of stainless-steel filter manifold $(\varnothing=30 \mathrm{~mm})$ with glass frit $(\varnothing=9 \mathrm{~mm})$ and glass funnel (V $=5 \mathrm{~mL}$ ). The dry deposited aerosol on stainless-steel circles was rinsed off with prefiltered MilliQ water and filtered through membrane filters $(0.2 \mu \mathrm{m}, \varnothing=47 \mathrm{~mm}$, Isopore, GTTP, Merck Millipore Ltd., Ireland). One half of the particulate matter was rinsed off by using split pliers and resuspended onto one to four Anodisc filters. The other half of the particles on the filters were stored in the fridge as a backup sample. Thus, subsamples corresponding to $50 \%$ of each wet and dry deposition sample were rinsed off and resuspended on Anodisc filters.

\section{$\mu F T I R$ analysis}

The samples on the Anodisc filters were measured with focal plane array (FPA) based micro-FourierTransform Infrared spectroscopy ( $\mu \mathrm{FTIR}$ ) with the IR microscope Hyperion 3000 (Bruker Inc., Billerica, USA) coupled to a Tensor 27 spectrometer (Bruker Optik GmbH, Ettlingen, Germany). The microscope was equipped with a $3.5 \times$ IR objective and liquid nitrogen cooled FPA detector operating with $64 \times 64$ pixels for chemical imaging described by Löder et al. [23] resulting in a pixel size of $11 \mu \mathrm{m}$. MP particles $(>11$ $\mu \mathrm{m})$ were analyzed in transmission mode on $\mathrm{a} \mathrm{CaF}_{2}$ transmission window ( $\varnothing=13 \mathrm{~mm}, \mathrm{~d}=2 \mathrm{~mm}$ ). Samples were scanned in the wavenumber range from 1250 to $3600 \mathrm{~cm}^{-1}$ with a spectral resolution of 8 $\mathrm{cm}^{-1}$ and an accumulation of 36 scans. Background was measured on the same filter in an area where no particles were observed. The entire particle-loaded filter area $\left(\sim 10 \times 10 \mathrm{~mm}^{2}\right)$ was scanned. Thus, an infrared map consisting of around 1 million individual spectra was acquired. Particle identification and quantification was done using the software OPUS 7.5 (Bruker Optik $\mathrm{GmbH}$ ) and ImageLab in combination with a non-commercial, custom-made software tool based on random forest decision classifiers as described by Hufnagl et al. [24, 25]. This commercially available software tool automatically searches for IR spectra of the 22 most common synthetic polymers. The location, major, and minor dimensions of the identified MP particles, colour, and polymer assignment were recorded. All FTIR spectra were compared with reference spectra from a database and only well-fitted spectra were assigned as MPs. Each automatically identified microplastic particle was manually double-checked against reference spectra according to a four-eye principle by experienced personal for quality assurance.

\section{Raman analysis}

Exemplarily, one filter from the August dry deposition sample was selected and used for extensive Raman measurements to probe for plastic particles smaller than $11 \mu \mathrm{m}$ in diameter. Wet deposition samples were in-situ filtered through a $10 \mu \mathrm{m}$ stainless-steel filter, and such in-depth studies by Raman spectroscopy were not applicable.

We scanned an Anodisc filter, which was also used for $\mu$ FTIR analysis. No additional particle resuspension on a substrate more appropriate for Raman imaging was conducted. Low Raman background and flatness of the Anodisc filter, which is crucial for the narrow focal depth analyses, enabled further Raman imaging investigations [26]. 
For Raman measurements a WITec alpha 300 RA+ imaging system (WITec GmbH, Ulm, Germany), equipped with a UHTS 300 spectrometer and a back-illuminated Andor Newton 970 EMCCD camera was employed. An excitation wavelength of $\lambda=532 \mathrm{~nm}$ and a 50x objective (Zeiss EC Epiplan-Neofluoar HD, $\mathrm{NA}=0.8)$ together with the WITec suite FIVE 5.3 software package were used for all measurements. The WITec ParticleScout particle analysing tool together with the WITec TrueMatch data base managing software (ST Japan, SPECARB and in-house polymer data bases) were utilized for MP detection and identification on the Anodisc filter sample.

Five randomly selected areas on the filter were chosen for Raman investigations (see Fig. 5a, areas 1, 2 and $3 a-c)$. An optical stitching image was taken over an area of $3 \times 3 \mathrm{~mm}^{2}$ and was scanned, employing the WITec ParticleScout particle analysing software (Fig. 5, area 1, red square). In this area, Raman spectra were acquired automatically followed by screening of the obtained Raman spectra with the TrueMatch database managing software. In addition, the identified MP were measured manually using an integration time of $0.5 \mathrm{sec}$ and 50 accumulations (laser power: $5 \mathrm{~mW}$ ). At selected four positions, large area Raman mapping was performed in order to probe for particles with sizes well below $5 \mu \mathrm{m}$ employing following conditions: i) scan area $500 \times 500 \mu \mathrm{m}^{2}$, integration time $0.8 \mathrm{sec}$, step size $2 \mu \mathrm{m}$ pixel ${ }^{-1}$, laser power $10 \mathrm{~mW}$ (Fig 5, area 2, blue square); ii) scan area $100 \times 100 \mu \mathrm{m}^{2}$, integration time 0.6 sec, step size $0.5 \mu \mathrm{m}$ pixel $^{-1}$, laser power: $8 \mathrm{~mW}$ (Fig. 5, areas 3a-c, white squares). For all large area scans the focus was set close to the filter surface in order to be able to probe the presence of small particles. The component distributions in large area scans were determined using the True Component Analysis option in the WITec Project FIVE 5.3 software. All spectra were subjected to a cosmic ray removal routine and baseline correction.

\section{Calculations \& statistical analysis}

MP wet and dry number and mass DFs were calculated according to Kernchen et al. (2021) [13]. Shortly, MP wet and dry number DFs were calculated from the blank subtracted count of plastic particles in a sample divided by the exposed surface area of collection $\left(1.08 \times 10^{-2} \mathrm{~m}^{2}\right.$ for wet deposition samples and $8.01 \times 10^{-3} \mathrm{~m}^{2}$ for dry deposition samples) and duration of sampling (days). The mass DFs of MPs were calculated from the blank subtracted calculated mass of plastic particles in a sample divided by the exposed surface area and duration of sampling. The mass of an individual particle was calculated by multiplying the density of the polymer type and the particle volume. The particles were assumed elliptical cylinders with a height of $67 \%$ of the minor dimension similarly as in work by Simon et al. for ellipsoid shape [27]. The total deposition was calculated by summing the wet and dry deposition. MP concentrations in precipitation were calculated by dividing MP amount in a sample to collected precipitation volume and multiplying to total precipitation amount per $\mathrm{m}^{2}$ over each sampling period. For calculations of dry deposition velocities please refer to Supplementary information. 24-hour air mass back trajectories were calculated using the air parcel trajectory model HYSPLIT4 (42) and NCEP/NCAR reanalysis data (43). Trajectory-averaged population densities were determined for each sampling period according to the following procedure: (i) For each day of the sampling period, eight 24-hour back 
trajectories were calculated arriving at 00:00, 03:00, 06:00, 09:00, 12:00, 15:00, 18:00, and 21:00 at $100 \mathrm{~m}$ above ground level at the study site in Kassel. (ii) For each 24-hour back trajectory, the trajectory-averaged population density was calculated from the 24 population densities determined hourly along the air mass trajectory. Every hour, the population density (number of people per square kilometre) at the air parcel position was taken from the German Census data 2011 on a $1 \mathrm{~km} \times 1 \mathrm{~km}$ grid (44), and averaged. Less than $5 \%$ of the air parcel positions along the 24 -hour back trajectories were outside of Germany, and ignored. (iii) For the entire sampling period, all trajectory-averaged population densities of all sampling days were averaged. Relationships between DFs and meteorological variables were estimated by means of Spearman rank correlations. Two means were tested using student's significant $t$-test with a significance level set at 0.05.All statistical analyses were performed with the freely available statistical computing software Past (v.4.03).

\section{Results And Discussion}

\section{Wet and dry deposition of MPs $>11 \mu \mathrm{m}$}

In the studied year, only a small amount of MP particles $>11 \mu \mathrm{m}$ in the shape of fragments were detected in all monthly collected wet deposition samples and in 5 out of 12 dry deposition samples (Table 1). In total, 8 particles found in dry deposition samples and 13 particles in wet deposition samples were assigned to common synthetic polymers, therefore, all statements based on particle count should be taken with some caution. The average particle size in wet deposition samples $(50 \pm 37 \mu \mathrm{m}$, mean $\pm S D)$ was slightly larger than the average particle size in dry deposition samples $(45 \pm 21 \mu \mathrm{m}$, mean $\pm S D)$ but not significantly different $(t$-test, $p>0.05)$. MP particles $<100 \mu \mathrm{m}$ were observed both in dry and wet deposition samples, whereas particles larger than $100 \mu \mathrm{m}$ were identified in wet deposition samples only. Calculated dry deposition velocities ranged from 0.05 to $0.2 \mathrm{~m} \mathrm{~s}^{-1}$.

Table 1 MP fragments detected in wet and dry atmospheric deposition samples using $\mu F T I R$ down to 11 $\mu \mathrm{m}$ 


\begin{tabular}{|c|c|c|c|c|c|c|c|c|c|}
\hline \multirow[t]{2}{*}{ Sample } & \multicolumn{4}{|c|}{ MPs detected in wet deposition } & \multicolumn{5}{|c|}{ MPs detected in dry deposition } \\
\hline & $\begin{array}{l}\text { Plastic } \\
\text { type }\end{array}$ & $\begin{array}{l}\text { Max. } \\
{[\mu \mathrm{m}]}\end{array}$ & $\begin{array}{l}\text { Min. } \\
{[\mu \mathrm{m}]}\end{array}$ & Colour & $\begin{array}{l}\text { Plastic } \\
\text { type }\end{array}$ & $\begin{array}{l}\text { Max. } \\
{[\mu \mathrm{m}]}\end{array}$ & $\begin{array}{l}\text { Min. } \\
{[\mu \mathrm{m}]}\end{array}$ & Colour & $\begin{array}{l}\text { Dry deposition } \\
\text { velocity }\left[\mathrm{m} \mathrm{s}^{-1}\right]\end{array}$ \\
\hline May-19 & PP & 44 & 22 & white & n. d. & n. d. & n. d. & n. d. & \\
\hline \multirow[t]{2}{*}{ Jun-19 } & PBT & 11 & 11 & grey & n. d. & n. d. & n. d. & n. d. & \\
\hline & PP & 60 & 27 & grey & & & & & \\
\hline Jul-19 & PP & 34 & 27 & grey & n. d. & n. d. & n. d. & n. d. & \\
\hline \multirow[t]{3}{*}{ Aug-19 } & PP & 22 & 11 & transp. & PP & 33 & 22 & grey & 0.061 \\
\hline & $\mathrm{PE}$ & 130 & 50 & grey & PP & 33 & 33 & transp. & 0.065 \\
\hline & PP & 111 & 45 & transp. & & & & & \\
\hline \multirow[t]{3}{*}{ Sep-19 } & $\mathrm{PE}$ & 22 & 11 & transp. & PVC & 11 & 11 & grey & 0.053 \\
\hline & $\mathrm{PE}$ & 56 & 35 & transp. & PP & 66 & 45 & transp. & 0.222 \\
\hline & PP & 27 & 19 & white & PP & 44 & 11 & transp. & 0.056 \\
\hline Oct-19 & PP & 70 & 43 & grey & PP & 45 & 25 & transp. & 0.063 \\
\hline Nov-19 & PE & 11 & 11 & grey & n. d. & n. d. & n. d. & n. d. & \\
\hline Dec-19 & PE & 45 & 45 & grey & SI & 46 & 32 & grey & 0.066 \\
\hline Jan-20 & n. a. & n. a. & n. a. & n. a. & n. d. & n. d. & n. d. & n. d. & \\
\hline Feb-20 & n. a. & n. a. & n. a. & n. a. & PC & 81 & 62 & black & 0.228 \\
\hline Mar-20 & n. a. & n. a. & n. a. & n. a. & n. d. & n. d. & n. d. & n. d. & \\
\hline Apr-20 & n. a. & n. a. & n. a. & n. a. & n. d. & n. d. & n. d. & n. d. & \\
\hline
\end{tabular}

Max. and Min. - maximum and minimum dimension of the MP particle; transp. - transparent; $n$. d. - not detected, n. a. - not analyzed; PP - polypropylene; PE - polyethylene; PBT - poly(butylene terephthalate); PVC - poly(vinyl chloride), SI - silicone; PC - polycarbonate.

Close to MP sources, efficient gravitational settling of MP particles $>100 \mu \mathrm{m}$ should be expected under dry conditions, while transport distances of these large particles are generally small. Brahney et al. (2020) noted similar observations for deposition to protected areas in the US. The plastics deposited under dry conditions were smaller and potentially subjected to long-range transport [21]. However, it is accepted that wet deposition favours the scavenging of smaller particles of the same chemical composition [16]. No fibres, but plastic fragments only were detected in wet and dry deposition samples, which is consistent with findings in the Hamburg metropolitan area, where $95 \%$ of all detected MPs in the total deposition were in the form of fragments [28]. 
In the period from May 2019 to April 2020, calculated number wet DFs varied between $5 \mathrm{MPs} \mathrm{m}^{-2}$ day $^{-1}$ and $19 \mathrm{MPs} \mathrm{m}^{-2}$ day $^{-1}\left(10 \pm 5 \mathrm{MPs} \mathrm{m}^{-2}\right.$ day $^{-1}$, mean $\left.\pm \mathrm{SD}\right)$, whereas dry DFs ranged between 0 and 23 MPs $\mathrm{m}^{-2}$ day $^{-1}\left(5 \pm 7 \mathrm{MPs} \mathrm{m}^{-2}\right.$ day $^{-1}$, mean \pm SD) (Fig. 1a). Note that wet deposition samples from January to April 2020 are missing due to technical problems, while all 12 monthly dry deposition samples are considered. In 5 out of 8 monthly measurements, the wet DFs of MP exceeded the corresponding dry DFs. However, in all four months when MP particles were identified both in dry and wet deposition samples (Aug, Sep, Oct, Dec), wet and dry DFs were similar. Overall, the wet deposition from May to December was $62 \%$ of the total (wet + dry) MP number atmospheric deposition. This value is in the range of the typical estimate of one-half of the total input of pollutant surface flux by wet deposition (18) and the estimated loss of submicron particles by wet deposition of greater than $80 \%$ used in atmospheric models [29].

The seasonal variation of dry deposition was similar to that of wet deposition. Among the wet/dry deposition measurements from May to December, the highest MP total DFs were observed in August and September.

MP concentrations in precipitation varied from 2 to $18 \mathrm{MPs} \mathrm{L}^{-1}$ (Fig. $1 \mathrm{~b}$ ), reflecting higher concentrations in August and September. The lowest concentration of $2 \mathrm{MPs} \mathrm{L}^{-1}$ was found in May, and the precipitation weighted mean concentration was $7 \pm 5 \mathrm{MPs} \mathrm{L}^{-1}$ (mean $\pm S D$ ). Thus, based on our samples, the estimated annual plastic wet deposition at the study site comprises $4284 \mathrm{MPs} \mathrm{m}^{-2} \mathrm{a}^{-1}$. Daily precipitation sums can be found in Supplementary information Fig. S1.

Mass DFs showed similar trends (SM, Fig. S3). For the detected MP particles that exist as supermicron (coarse) particles $(>11 \mu \mathrm{m})$, wet deposition dominates the total mass flux at the study site, comprising 70 $\%$ of the total plastic mass deposition (from May to December 2019).

\section{Correlation of MP DFs and concentrations in precipitation with meteorological conditions and population density}

Dry and wet DFs are affected by a multitude of factors. Dry DFs depend on particle deposition velocities, small-scale meteorological effects near the surface, surface characteristics, and atmospheric stability and friction velocity, which are influenced by variables such as particle size, wind speed, and temperature [30]. Coarse atmospheric particles in the diameter range larger than $10 \mu \mathrm{m}$ mainly deposit by gravitational settling and impaction or interception [31]. In contrast, the scavenging efficiency by wet deposition was found to be related to the duration and intensity of the precipitation event, as well as to the hydrometeor size distribution, the settling speed, the average collection efficiency, the shape of the hydrometeors and aerosol hydrophilicity [32-34]. Moreover, Wu et. al (2018) found that removal of particles smaller than $2.5 \mu \mathrm{m}$ by wet deposition to be more efficient than by dry deposition [35].

We investigated the relationship between dry and wet DFs, concentrations in precipitation, and meteorological variables by means of Spearman rank correlation analysis. MP dry DFs did not correlate significantly with temperature, wind speed, $\mathrm{RH}$, and with none of the other studied meteorological 
parameters (Table 2, expanded table in Supplementary information, Table S2). Furthermore, wet DFs did not show significant correlations with precipitation amount, intensity, or duration but showed a strong negative correlation with the maximal dry period, i. e. the longest continuous period without precipitation during sampling intervals $\left(r_{s}=-0.96, p=0.0009\right)$. This points to low accumulation capability for MP particle $>11 \mu \mathrm{m}$ in the atmosphere. Coarse MP particles tend to sediment faster and since no positive correlation between dry DFs and maximal dry period was observed, MP sources might have local and temporally irregular emission patterns.

Table 2 Correlation between meteorological variables and microplastic dry, wet, and total DFs, and concentrations in precipitation*

\begin{tabular}{|c|c|c|c|c|}
\hline Parameter & $\begin{array}{l}\text { MP dry DF } \\
{\left[\mathrm{MPs} \mathrm{m}^{-2}\right.} \\
\left.\text { day }^{-1}\right]\end{array}$ & $\begin{array}{l}\text { MP wet DF } \\
{\left[\text { MPs m }^{-2}\right.} \\
\text { day }^{-1} \text { ] }\end{array}$ & $\begin{array}{l}\text { MP total } \\
\text { DF } \\
{\left[\text { MPs m }^{-2}\right.} \\
\left.\text { day }^{-1}\right]\end{array}$ & $\begin{array}{l}\text { MP concentration in precipitation } \\
{\left[\mathrm{MPs} \mathrm{L}^{-1}\right]}\end{array}$ \\
\hline $\begin{array}{l}\text { Average dry period } \\
\text { [days] }\end{array}$ & -0.56 & -0.21 & -0.42 & -0.12 \\
\hline $\begin{array}{l}\text { Maximal dry period } \\
\text { [days] }\end{array}$ & -0.40 & -0.96 & -0.61 & -0.68 \\
\hline $\begin{array}{l}\text { Average wet period } \\
\text { [h] }\end{array}$ & -0.09 & -0.58 & -0.40 & -0.87 \\
\hline $\begin{array}{l}\text { Maximal wet period } \\
\text { [h] }\end{array}$ & 0.16 & -0.28 & -0.05 & -0.58 \\
\hline Precipitation [mm] & 0.29 & -0.41 & -0.20 & -0.78 \\
\hline Wind speed $\left[\mathrm{m} \mathrm{s}^{-1}\right]$ & -0.04 & -0.19 & 0.02 & -0.55 \\
\hline Temperature $\left[{ }^{\circ} \mathrm{C}\right]$ & 0.17 & 0.09 & 0.03 & 0.34 \\
\hline $\begin{array}{l}\text { Relative humidity } \\
{[\%]}\end{array}$ & 0.17 & 0.07 & 0.17 & -0.09 \\
\hline
\end{tabular}

*Spearman rank correlation coefficients between meteorological variables and MP DFs and concentrations in precipitation: $p<0.05$ (in red), $p>0.05$ (in black)

MP concentrations in precipitation showed negative correlation with the precipitation amount and average wet period (Table 2). This indicates dilution of precipitation samples and efficient MP scavenging by precipitation.

The dominant wind direction for the study period in relation to the MP total DFs is shown in Fig. 2. The wind rose plot for the study site and timeframe indicates that the prevailing wind direction was NE and SSW (see also Supplementary information, Fig. S4). In May and July 2019, and in March and April 2020 the dominant wind was blowing from the NE, and in the other months from the SSW. During the 
dominance of SSW wind, we collected $92 \%$ of all detected MP particles in the total (wet + dry) deposition, $86 \%$ of all MP particles in wet deposition, and $100 \%$ of MP particles in dry deposition samples. The city centre of Kassel is SW of the sampling site; thus, the dominant SSW winds may provide the most probable vector for local MP pollution at the sampling site. Calculated deposition velocities of detected plastic particles in dry deposition samples ranged from 0.05 to $0.2 \mathrm{~m} \mathrm{~s}^{-1}$ (see Table 1), indicating relatively short-range transport phenomena. This supports the idea that MP pollution $(>11 \mu \mathrm{m})$ to the study site was brought from the nearest urban centre.

Since single-point local wind fields can be misleading and can differ from the regional wind conditions, air mass origin was also evaluated by calculating 24-hour back trajectories for the study site and sampling periods. Anthropogenic influence on MP DFs may be estimated by averaging population densities along air mass back trajectories during each sampling period. Fig. 3 shows the monthly evolution of MP DFs (dry DF, wet DF, total DF), of MP concentrations in precipitation, and of the trajectoryaveraged population density during the sampling periods. MP concentrations in precipitation were higher when air masses arrived from more densely populated areas and correlated significantly with the trajectory-averaged population density $\left(r_{s}=0.91, \mathrm{p}=0.002\right.$, Supplementary information, Table S3). Thus, anthropogenic activities appear to contribute to airborne MP abundances.

\section{Polymer type}

In total, six different polymer types were found in wet and dry deposition samples by $\mu F T I R$, and polypropylene (PP) particles predominated in both deposition modes (Fig. 4).

Minor fractions of the polymer-type distribution differ among the deposition modes. In wet deposition samples, polyethylene (PE) and poly(butylene terephthalate) (PBT) particles were detected, whereas particles made of poly(vinyl chloride) (PVC), polycarbonate (PC), and silicone-based compounds (SI) were detected in dry deposition samples only. Since MP particle sizes were similar in wet and dry deposition samples, we cannot explain the observed variation due to particle size. If MP particles would be scavenged by cloud droplets in the free troposphere, the particles observed in precipitation might differ from those removed from the boundary layer by dry deposition [36]. However, we propose that variable MP emission patterns and the low number of detected MP particles are the main factors leading to compositional differences among the minor components in wet and dry deposition samples. A study by Brahney et al. in 2020 [21] suggests that wet-deposited MPs originate from different source regions than those that are dry deposited (studied particle size $\geq 4 \mu \mathrm{m}$ ). Wet plastic DFs were significantly correlated to population metrics, as determined by the intersection of the air mass with population centres, whereas dry deposition correlated negatively with regional dust DFs and suggests that dry-deposited plastics are subject to large-scale, global transport. Regarding wet deposition, our findings are consistent with the work by Brahney et al.

PE particles scavenged by precipitation comprised $38 \%$, but no PE particles were detected in dry deposition samples, while PP particles were observed in similar amounts in both wet and dry deposition. 
We expect that dry deposition mechanisms for PP and PE particles do not differ strongly and that particles of all studied sizes are removed by dry deposition independent of chemical composition. PE and PP polymers have similar densities, and they were detected as fragments in both removal modes, so significant differences in settlings velocities due to shape are not expected. However, we expect that all atmospheric MP particles will quickly age and form surface coatings, e. g. by condensation of lowvolatile compounds. The surface properties of ambient plastic particles can thus change significantly compared to the native polymer, making particle deposition difficult to assess. Moreover, airborne MP originated from marine or freshwater systems for example via bubble-bursting or raindrop impacts (e.g. [37]) possess most likely reduced hydrophobicity due to an eco-corona increasing the density and surface charge of particles [38,39], or a biofilm [40], which typically features a rather sticky matrix of extracellular polymeric substances [41] and may support adhesion to other airborne particulates. The ability to form larger particle aggregates, which may support dry deposition due to the increased settling velocities, is likely similar to both plastic types. Thus, we believe that temporal variation in plastic emission is the crucial factor determining the composition of plastics in wet and dry deposition samples. However, further research is required to investigate the potential role of chemical composition of plastic particles, aging degree as well as size in wet and dry removal mechanisms.

\section{Exemplary Raman analysis of dry deposited MP}

It may be expected that MP particle numbers are underestimated by the sole application of $\mu \mathrm{FTIR}$ having a detection limit around $10 \mu \mathrm{m}$ since several studies confirmed an increase in airborne MP particle numbers with decreasing particle size $[42,43]$. Unfortunately, most of the current analytical techniques used for MP identification are limited with respect to particle size. [43]. Detecting plastic particles in the size range most relevant for inhalation $(<10 \mu \mathrm{m})$ is time-consuming and expensive [2]. Therefore, the vast majority of studies focusing on airborne MP use techniques with an analytical threshold of particle diameters $>10 \mu \mathrm{m}$. Only a few methods are suitable for the detection of polymer fragments in the lower $\mu \mathrm{m}$-range (between $10 \mu \mathrm{m}$ and $1 \mu \mathrm{m}$ ), submicron range (between $1 \mu \mathrm{m}$ and $100 \mathrm{~nm}$ ), and ultrafine or nano range ( $\leq 100 \mathrm{~nm}$ ), and up to date lack the routine methodology [44]. Currently, by using Raman imaging the smallest MP particles measured in a real sample were down to $100 \mathrm{~nm}$ in size [45]. FTIR and Raman spectroscopy are the most frequently applied methods in MP studies, and it has been suggested to use them in tandem for complete and reliable chemical characterization of microplastics [46]. Even though both methods are vibrational spectroscopic methods, they complement each other and may provide different numbers and polymer types of detectable MPs. In this study, Raman spectroscopy was applied in order to gain insight into the abundance of dry deposited MP particles in the size range $<11$ $\mu \mathrm{m}$, i. e. particles which may enter the respiratory system via inhalation and may therefore affect human health [47].

In total, 1361 particles were found over the selected area (Fig 5, area 1), employing the WITec ParticleScout particle-analysis tool of which 3 were assigned to plastics, i. e. polydimethylsiloxane (PDMS), poly(vinyl chloride) (PVC), and polypropylene (PP) (Fig. 5b). Thus, MP particles composed $0.2 \%$ of all analysed particles in this $3 \times 3 \mathrm{~mm}^{2}$ area (see also Supplementary information Fig. S5, S6). In 
comparison, scanning the entire particle loaded filter area by using $\mu \mathrm{FTIR}$, only one PP particle (Fig. 5a, position 4) was detected (see also Supplementary information, Fig. S7).

Two identified particles made of PDMS $(14 \mu \mathrm{m} \times 4 \mu \mathrm{m})$ and PP $(9 \mu \mathrm{m} \times 9 \mu \mathrm{m})$ (Fig. 6a,c) fell in the size range where $\mu \mathrm{FTIR}$ is no longer applicable for reliable identification, but a slightly larger PVC particle (21 $\mu \mathrm{m} \times 15 \mu \mathrm{m})$ (Fig. 6b) was likely overlooked by $\mu$ FTIR. As suggested by Käppler et al. (2016) PVC particles seem better detectable by Raman spectroscopy compared to FTIR. This is potentially due to the characteristic relatively broad $\mathrm{C}-\mathrm{Cl}$ stretching vibration at $690 \mathrm{~cm}^{-1}$, which was not detectable due to the limited spectral range of the FPA detector $\left(4000-900 \mathrm{~cm}^{-1}\right)$ in $\mu \mathrm{FTIR}$ in their study, or categorised as another chemical especially when containing high amounts of plasticisers [46]. Most of the other particles showed Raman spectral patterns typical for inorganics i. e. black carbon (soot), quartz, titanium dioxide, and dolomite. Identified organic non-plastic particles were assigned to cellulose and bacteria (see Supplementary information, Fig. S6).

Extrapolation of these additional results to the total effective filter surface $\left(7.85 \times 10^{-5} \mathrm{~m}^{2}\right)$, sampling surface $\left(8.01 \times 10^{-3} \mathrm{~m}^{2}\right)$ and collection time (35 days) gave a total dry DF of 207 particles per $\mathrm{m}^{2}$ per day instead of $17 \mathrm{MPs} \mathrm{m}^{-2} \mathrm{~d}^{-1}$ as calculated from $\mu$ FTIR analysis only. Thus, FTIR analysis compared to Raman analysis may lead to underestimation of MP DFs by an order of magnitude; however, uncertainties due to the subsample analyses and extrapolation should be considered. Scanning a larger number of particles would give a more robust estimation of the dry DF. It was shown by other studies that FTIR imaging may lead to underestimation of MP number by about $35 \%$, especially in the size range $<20$ $\mu \mathrm{m}$ compared to Raman imaging [46], and automated single-particle exploration coupled to $\mu$-Raman (ASPEx- $\mu$-Raman) quantified two-times higher MP numbers in the size range $<500 \mu \mathrm{m}$ compared to FTIR imaging [48]. This suggests that Raman analyses might typically yield higher deposition fluxes compared to FTIR imaging.

The large area Raman scan with a step size of $2 \mu \mathrm{m} \mathrm{pixel}^{-1}$ (Fig. 5a, area $2\left(500 \times 500 \mu \mathrm{m}^{2}\right)$, enclosing PDMS MP particle) is presented in Fig. 7. As shown in Fig. 7b (also Supplementary information, Fig. S8), a large number of single particles in the lower micron range were detected. However, comparison of the particles' Raman spectra to the Raman spectra of the most common synthetic polymers did not result in a reliable particle assignment to plastics.

Moreover, large area Raman scans with a step size of $0.5 \mu \mathrm{m} \mathrm{pixel}^{-1}$ of three randomly selected $100 \times 100$ $\mu \mathrm{m}^{2}$ quadrants did not result in plastic particle assignment in the submicron range (component distribution from Raman imaging and respective Raman spectra for one quadrant are given exemplarily in Supplementary information, Fig. S9). Submicron-range particles made of quartz, calcite, soot, and most probably amylose or another polysaccharide were identified. If particles of the most common synthetic polymers would be present, the spectral assignment would be achieved (also in the submicron range). It is worth mentioning that only $0.04 \%$ of the sample area were scanned with a step size of 0.5 $\mu \mathrm{m}$ pixel $^{-1}$, and therefore, the analysed subsample is not representative. However, scanning only $1 \%$ of 
the filter area would require the analysis of 78 quadrants and $>500 \mathrm{~h}$ of instrumental time. With the applied spatially resolved detection of submicron particles it would take several days to scan a representative area of the sample. However, our filtration technique distributes the particles on the filter equally, and if a vast amount of submicron plastic particles would be deposited on the sampling area, we would be able to see at least some of them.

Our results suggest that atmospheric dry deposition samples do not contain a large number of fine plastic particles $>500 \mathrm{~nm}$. This is consistent with the lowest deposition velocities of atmospheric particles in the so-called accumulation range from $100 \mathrm{~nm}$ to $1 \mu \mathrm{m}$ [49]. Even if there is a large number of submicron MP particles in the atmosphere, reduced dry DFs must be expected. Further Raman mapping analyses of aerosol samples collected by active pump sampling would give new insights into the abundance of airborne submicron plastic particles.

\section{Conclusions And Outlook}

Dry and wet deposition processes of MP particles in the size range $>11 \mu \mathrm{m}$ were of similar range at a study site in Kassel, Central Germany. From May to December 2019, on average, wet removal mechanisms dominated and comprised $62 \%$ of the total number deposition and $70 \%$ of the total mass deposition of MP particles. The largest MP DFs were observed with the dominant winds from SSW, which may have passed over the urban centre of Kassel. MP concentrations in precipitation correlated significantly with the population density-weighted along air mass trajectories. This indicates a direct anthropogenic influence on atmospheric MP concentrations, however, further studies correlating atmospheric MP concentrations and air mass origin are required to validate these findings and ultimately to better constrain atmospheric MP emission sources. Variable MP emission patterns may lead to compositional variation between removal modes even if wet and dry deposition of MP particles in the size range $>11 \mu \mathrm{m}$ occurred from the same air volume.

Use of $\mu$ FTIR spectroscopy alone cannot reliably identify microplastics in atmospheric samples. MP DFs derived from $\mu \mathrm{FTIR}$ analysis (diameter $>11 \mu \mathrm{m}$ ) and Raman analysis including smaller particles may differ by an order of magnitude or more. Therefore, application of a combination of both $\mu$ FTIR and Raman spectroscopy is recommended to estimate the atmospheric loads and deposition of plastics. Dry deposition of lower micron and submicron plastic particles was not observed to be significant in this study; however, further research is needed to assess the concentrations and the effects of fine MP particles in the atmosphere.

\section{Abbreviations}

MP

microplastic

$\mu \mathrm{FTIR}$

micro-Fourier-Transform Infrared spectroscopy

Page 15/24 
DF

deposition flux

$\mathrm{PP}$

polypropylene

PE

polyethylene

PBT

poly(butylene terephthalate)

PVC

poly(vinyl chloride)

SI

silicone

PC

polycarbonate

PDMS

polydimethylsiloxane.

\section{Declarations}

\section{Acknowledgements}

The authors would like to thank Agnes Bednorz for technical support. Many thanks to Dr. Franziska Luschtinetz (Kasse/Wasser), for the collaboration and collection of the samples.

Author's contributions: A.H., C.L. and M.L. designed research; S.K., A.E, and H.S. performed research; S.K., M.L., H.S. and C.G. analysed data; S.K. wrote the paper and all co-authors revised the manuscript.

\section{Funding}

The authors are grateful to BMBF and DFG for the financial support and for the support extension due to the Coronavirus crisis. The project was supported by the Federal Ministry of Education and Research (BMBF). Project funding ref. nr: 03F0789A, acronym PLAWES. Part of this work was funded by the Deutsche Forschungsgemeinschaft (DFG, German Research Foundation) - project nr. 391977956 SFB1357.

\section{Availability of data and materials}

All data generated or analysed during this study are included in this published article [and its supplementary information files].

Competing interests

The authors declare that they have no competing interests. 


\section{References}

1. Manisalidis I, Stavropoulou E, Stavropoulos A, Bezirtzoglou E. Environmental and health impacts of air pollution: a review. Frontiers in public health. 2020;8:14.

2. Zhang S, Wang J, Liu X, Qu F, Wang X, Wang X, Li Y, Sun Y. Microplastics in the environment: A review of analytical methods, distribution, and biological effects. TrAC Trends in Analytical Chemistry. 2019;111:62-72.

3. Enyoh CE, Verla AW, Verla EN, Ibe FC, Amaobi CE. Airborne microplastics: a review study on method for analysis, occurrence, movement and risks. Environmental Monitoring and Assessment. 2019;191:668.

4. Huang Y, Qing X, Wang W, Han G, Wang J. Mini-review on current studies of airborne microplastics: Analytical methods, occurrence, sources, fate and potential risk to human beings. TrAC Trends in Analytical Chemistry. 2020;125:115821.

5. Prata JC. Airborne microplastics: consequences to human health? Environmental pollution. 2018;234:115-126.

6. Trainic M, Flores JM, Pinkas I, Pedrotti ML, Lombard F, Bourdin G, Gorsky G, Boss E, Rudich Y, Vardi A. Airborne microplastic particles detected in the remote marine atmosphere. Communications Earth \& Environment. 2020;1:1-9.

7. Levermore JM, Smith TEL, Kelly FJ, Wright SL. Detection of microplastics in ambient particulate matter using Raman spectral imaging and chemometric analysis. Analytical Chemistry. 2020;92:8732-8740.

8. Cai L, Wang J, Peng J, Tan Z, Zhan Z, Tan X, Chen Q. Characteristic of microplastics in the atmospheric fallout from Dongguan city, China: preliminary research and first evidence. Environmental Science and Pollution Research. 2017;24:24928-24935.

9. Wright SL, Ulke J, Font A, Chan KL, Kelly FJ. Atmospheric microplastic deposition in an urban environment and an evaluation of transport. Environment international. 2020;136:105411.

10. Bergmann M, Mützel S, Primpke S, Tekman MB, Trachsel J, Gerdts G. White and wonderful? Microplastics prevail in snow from the Alps to the Arctic. Science Advances. 2019;5:eaax1157.

11. Revell LE, Kuma P, Le Ru EC, Somerville WRC, Gaw S. Direct radiative effects of airborne microplastics. Nature. 2021;598:462-467.

12. Anbumani S, Kakkar P. Ecotoxicological effects of microplastics on biota: a review. Environmental Science and Pollution Research. 2018;25:14373-14396.

13. Kernchen S, Löder MGJ, Fischer F, Fischer D, Moses SR, Georgi C, Nölscher AC, Held A, Laforsch C. Airborne microplastic concentrations and deposition across the Weser River catchment. Science of the Total Environment. 2021:151812.

14. Goodman KE, Hare JT, Khamis ZI, Hua T, Sang Q-XA. Exposure of Human Lung Cells to Polystyrene Microplastics Significantly Retards Cell Proliferation and Triggers Morphological Changes. Chemical Research in Toxicology. 2021;34:1069-1081. 
15. Jorgensen SE, Fath BD. Encyclopedia of ecology: Newnes; 2014.

16. Hosker Jr RP, Lindberg SE. Atmospheric deposition and plant assimilation of gases and particles. Atmospheric Environment (1967). 1982;16:889-910.

17. Dris R, Gasperi J, Mirande C, Mandin C, Guerrouache M, Langlois V, Tassin B. A first overview of textile fibers, including microplastics, in indoor and outdoor environments. Environmental pollution. 2017;221:453-458.

18. Allen S, Allen D, Phoenix VR, Le Roux G, JimÃ@nez PD, Simonneau A, Binet S, Galop D. Atmospheric transport and deposition of microplastics in a remote mountain catchment. Nature Geoscience. 2019;12:339-344.

19. Dris R, Gasperi J, Saad M, Mirande C, Tassin B. Synthetic fibers in atmospheric fallout: a source of microplastics in the environment? Marine Pollution Bulletin. 2016;104:290-293.

20. Roblin B, Ryan M, Vreugdenhil A, Aherne J. Ambient Atmospheric Deposition of Anthropogenic Microfibers and Microplastics on the Western Periphery of Europe (Ireland). Environmental science \& technology. 2020;54:11100-11108.

21. Brahney J, Hallerud M, Heim E, Hahnenberger M, Sukumaran S. Plastic rain in protected areas of the United States. Science. 2020;368:1257-1260.

22. Abbasi S, Turner A. Dry and wet deposition of microplastics in a semi-arid region (Shiraz, Iran). Science of the Total Environment. 2021;786:147358.

23. Löder MGJ, Kuczera M, Mintenig S, Lorenz C, Gerdts G. Focal plane array detector-based microFourier-transform infrared imaging for the analysis of microplastics in environmental samples. Environmental Chemistry. 2015;12:563-581.

24. Hufnagl B, Steiner D, Renner E, Löder MGJ, Laforsch C, Lohninger H. A methodology for the fast identification and monitoring of microplastics in environmental samples using random decision forest classifiers. Analytical Methods. 2019;11:2277-2285.

25. Hufnagl B, Stibi M, Martirosyan H, Wilczek U, Möller JN, Löder MGJ, Laforsch C, Lohninger H. Computer-Assisted Analysis of Microplastics in Environmental Samples Based on $\mu F T I R$ Imaging in Combination with Machine Learning. Environmental Science \& Technology Letters. 2021;9:90-95.

26. Zada L, Leslie HA, Vethaak AD, Tinnevelt GH, Jansen JJ, Boer JF de, Ariese F. Fast microplastics identification with stimulated Raman scattering microscopy. Journal of Raman spectroscopy. 2018;49:1136-1144.

27. Simon M, van Alst N, Vollertsen J. Quantification of microplastic mass and removal rates at wastewater treatment plants applying Focal Plane Array (FPA)-based Fourier Transform Infrared (FTIR) imaging. Water research. 2018;142:1-9.

28. Klein M, Fischer EK. Microplastic abundance in atmospheric deposition within the Metropolitan area of Hamburg, Germany. Science of the Total Environment. 2019;685:96-103.

29. Emerson EW, Hodshire AL, DeBolt HM, Bilsback KR, Pierce JR, McMeeking GR, Farmer DK. Revisiting particle dry deposition and its role in radiative effect estimates. Proceedings of the National Academy of Sciences. 2020;117:26076-26082. 
30. Mariraj Mohan S. An overview of particulate dry deposition: measuring methods, deposition velocity and controlling factors. International journal of environmental science and technology. 2016;13:387402 .

31. Droppo JG. Improved formulations for air-surface exchanges related to National Security Needs: dry deposition models; 2006.

32. Jennings SG, Harrison RM, van Grieken R. Wet processes affecting atmospheric aerosols. Atmospheric particles. 1998:475-508.

33. Andronache $\mathrm{C}$. Estimates of sulfate aerosol wet scavenging coefficient for locations in the Eastern United States. Atmospheric environment. 2004;38:795-804.

34. Feng J. A size-resolved model for below-cloud scavenging of aerosols by snowfall. Journal of Geophysical Research: Atmospheres. 2009;114.

35. Wu Y, Liu J, Zhai J, Cong L, Wang Y, Ma W, Zhang Z, Li C. Comparison of dry and wet deposition of particulate matter in near-surface waters during summer. PloS one. 2018;13:e0199241.

36. Chand D, Guyon P, Artaxo P, Schmid O, Frank GP, Rizzo LV, Mayol-Bracero OL, Gatti LV, Andreae MO. Optical and physical properties of aerosols in the boundary layer and free troposphere over the Amazon Basin during the biomass burning season. Atmospheric Chemistry and Physics. 2006;6:2911-2925.

37. Lehmann M, Oehlschlägel LM, Häusl FP, Held A, Gekle S. Ejection of marine microplastics by raindrops: a computational and experimental study. Microplastics and Nanoplastics. 2021;1:1-19.

38. Galloway TS, Cole M, Lewis $\mathrm{C}$. Interactions of microplastic debris throughout the marine ecosystem. Nature ecology \& evolution. 2017;1:1-8.

39. Ramsperger A, Narayana VKB, Groß W, Mohanraj J, Thelakkat M, Greiner A, Schmalz H, Kress H, Laforsch C. Environmental exposure enhances the internalization of microplastic particles into cells. Science Advances. 2020;6:eabd1211.

40. Harrison JP, Hoellein TJ, Sapp M, Tagg AS, Ju-Nam Y, Ojeda JJ. Microplastic-associated biofilms: a comparison of freshwater and marine environments. In: Freshwater microplastics: Springer, Cham; 2018. pp. 181-201.

41. Michels J, Stippkugel A, Lenz M, Wirtz K, Engel A. Rapid aggregation of biofilm-covered microplastics with marine biogenic particles. Proceedings of the Royal Society B. 2018;285:20181203.

42. Mbachu O, Jenkins G, Pratt C, Kaparaju P. A new contaminant superhighway? A review of sources, measurement techniques and fate of atmospheric microplastics. Water, Air, \& Soil Pollution. 2020;231:1-27.

43. Zhang Y, Kang S, Allen S, Allen D, Gao T, Sillanpää M. Atmospheric microplastics: A review on current status and perspectives. Earth-Science Reviews. 2020;203:103118.

44. Schwaferts C, Niessner R, Elsner M, Ivleva NP. Methods for the analysis of submicrometer-and nanoplastic particles in the environment. TrAC Trends in Analytical Chemistry. 2019;112:52-65. 
45. Sobhani Z, Zhang X, Gibson C, Naidu R, Megharaj M, Fang C. Identification and visualisation of microplastics/nanoplastics by Raman imaging (i): Down to $100 \mathrm{~nm}$. Water research. 2020;174:115658.

46. Käppler A, Fischer D, Oberbeckmann S, Schernewski G, Labrenz M, Eichhorn K-J, Voit B. Analysis of environmental microplastics by vibrational microspectroscopy: FTIR, Raman or both? Analytical and bioanalytical chemistry. 2016;408:8377-8391.

47. Anderson JO, Thundiyil JG, Stolbach A. Clearing the air: a review of the effects of particulate matter air pollution on human health. Journal of medical toxicology. 2012;8:166-175.

48. Cabernard L, Roscher L, Lorenz C, Gerdts G, Primpke S. Comparison of Raman and Fourier transform infrared spectroscopy for the quantification of microplastics in the aquatic environment.

Environmental science \& technology. 2018;52:13279-13288.

49. Seinfeld JH, Pandis SN. Atmospheric Chemistry and Physics: from air pollution to climate change.: New York. John Willey \& Sons; 1998.

\section{Figures}
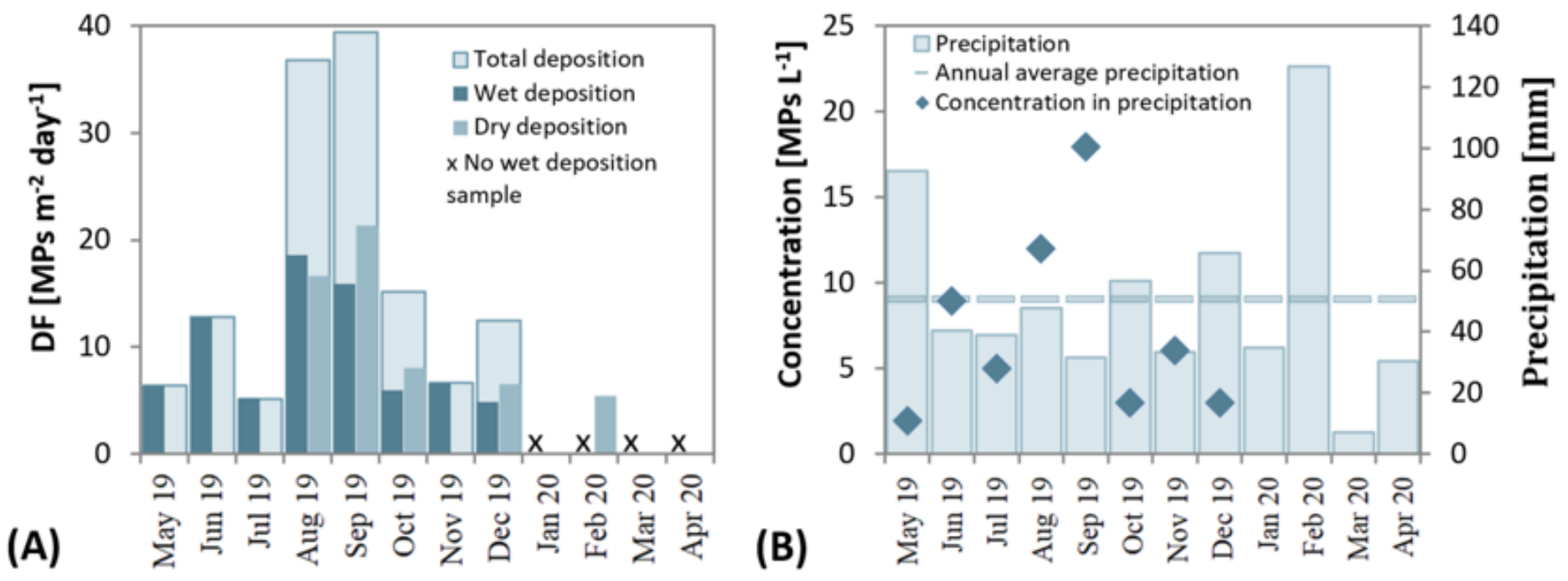

\section{Figure 1}

Monthly variation in (A) total (wet + dry), wet, and dry number atmospheric deposition of MPs, and (B) MP concentrations in precipitation and total precipitation patterns at the study site collected during the year 2019/2020 


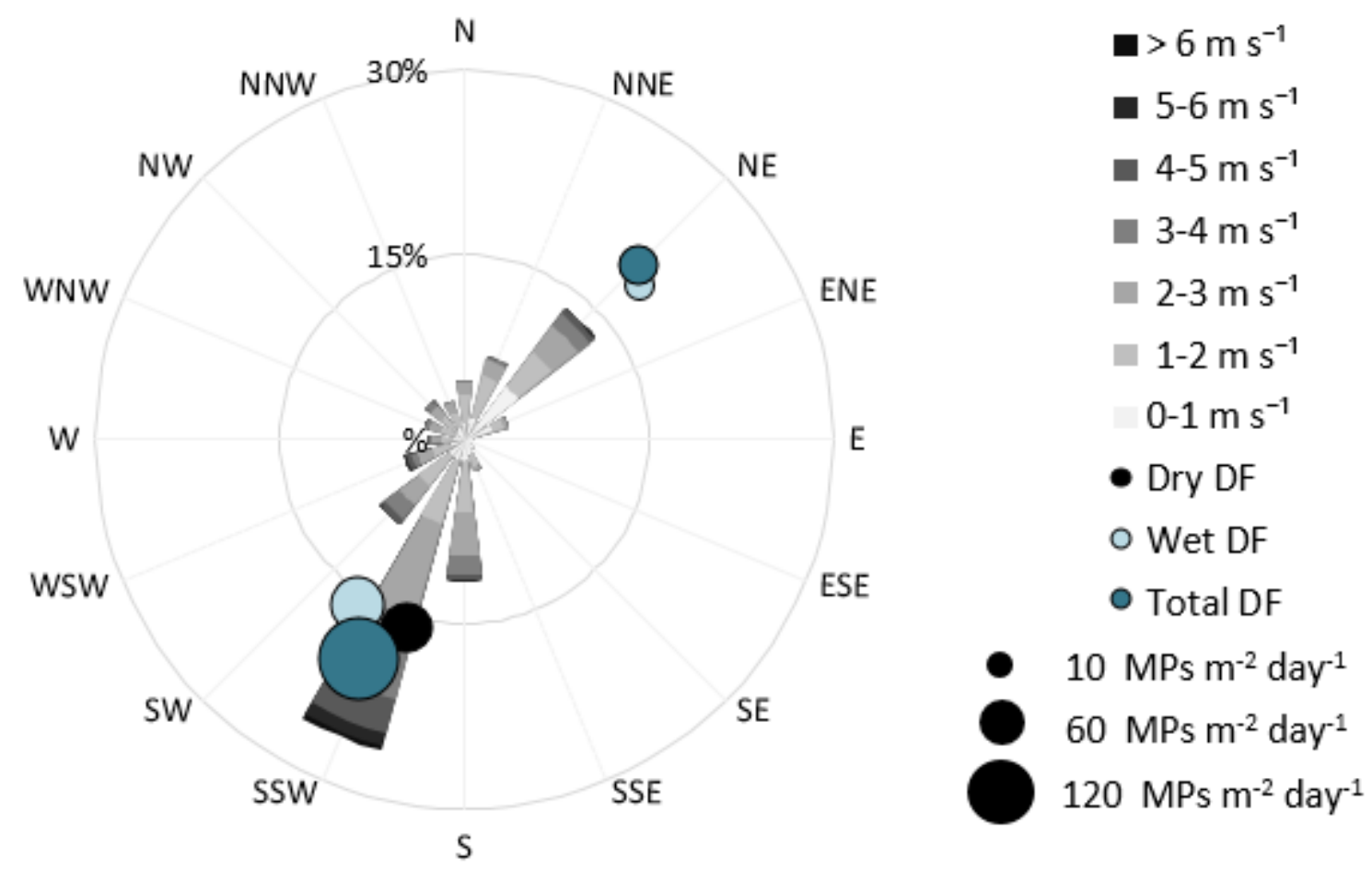

Figure 2

Windrose plot characterizing wind speed, direction, and frequency for the study conditions in relation to the MP number DFs

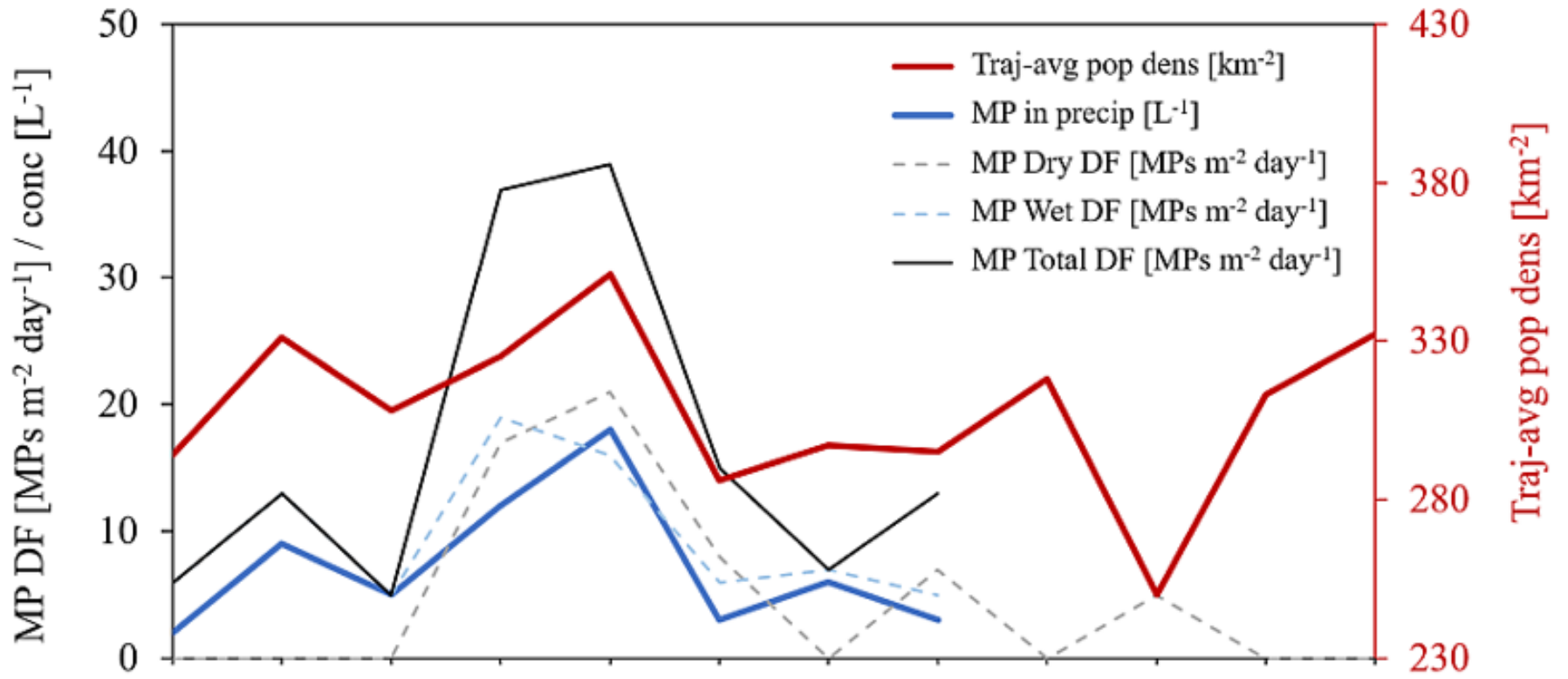

May 19 Jun 19 Jul 19 Aug 19 Sep 19 Oct 19 Nov 19 Dec 19 Jan 20 Feb 20 Mar 20 Apr 20

Figure 3 
Temporal evolution of trajectory-averaged population density (red line), MP concentration in precipitation (blue line), and MP dry, wet and total DFs (broken grey and blue, solid black lines)
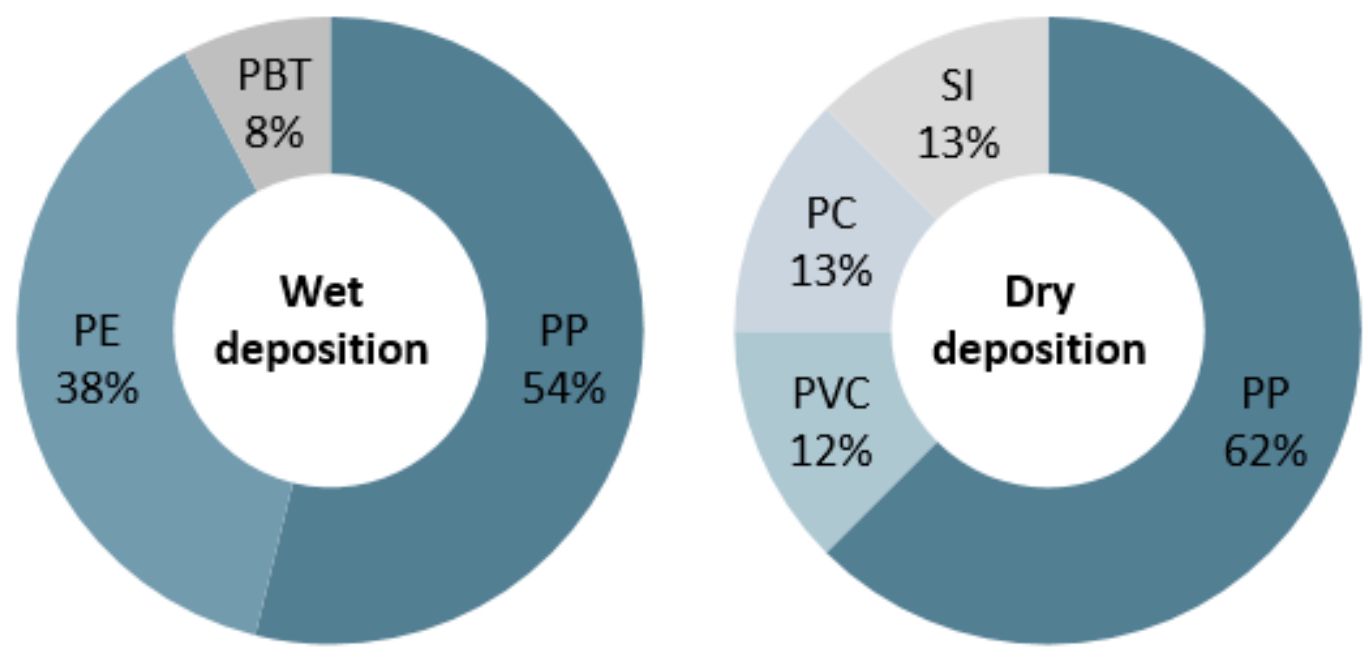

\section{Figure 4}

Polymer type distribution among the dry (right) and wet (left) deposition samples

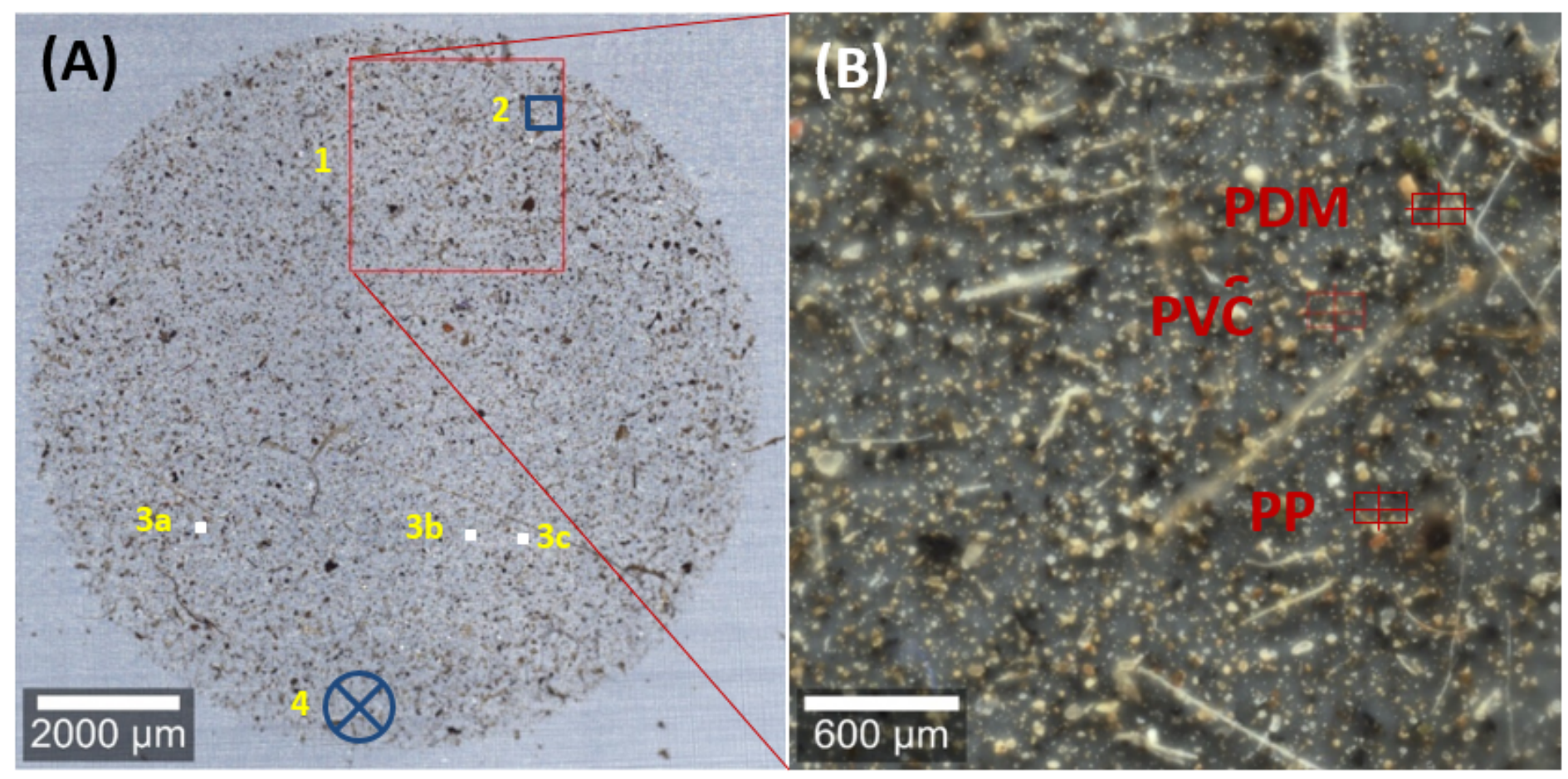

Figure 5 
(A) Optical microscopy stitching image of the selected filter showing the area (position 1, red square) employed for particle analysis with WITec ParticleScout, Raman imaging areas (position 2, blue square, and positions 3a-c, white squares), and the location of the PP particle found by $\mu \mathrm{FTIR}$ (position 4, blue circle); (B) dark-field optical microscopy stitching image of area 1 in (a), being screened with WITec ParticleScout, and the position of detected MP particles
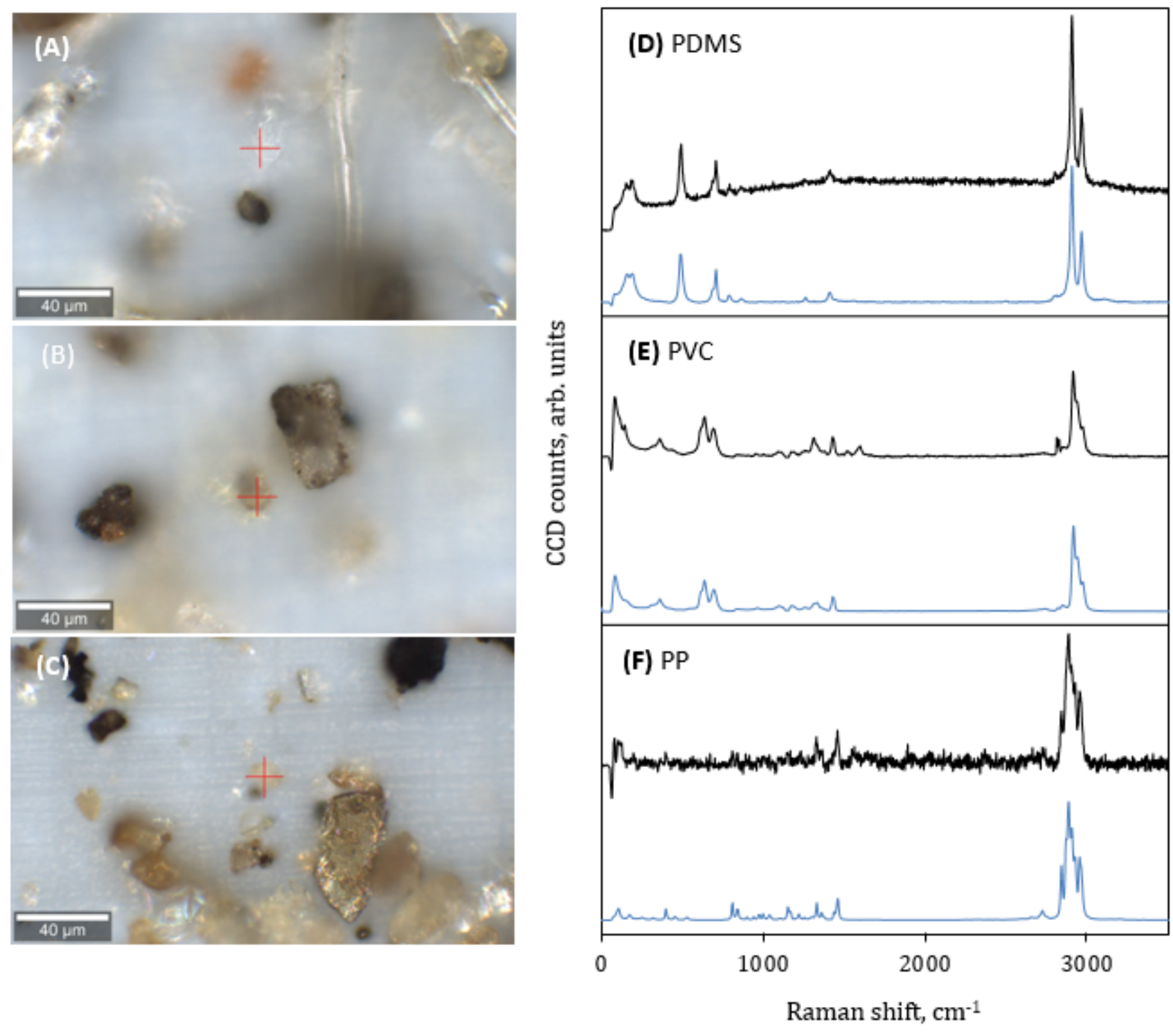

Figure 6

Optical microscopy images of the detected (A) PDMS, (B) PVC, and (C) PP microplastic particles and (DF) corresponding Raman spectra (black) compared to reference spectra from the database (blue) 

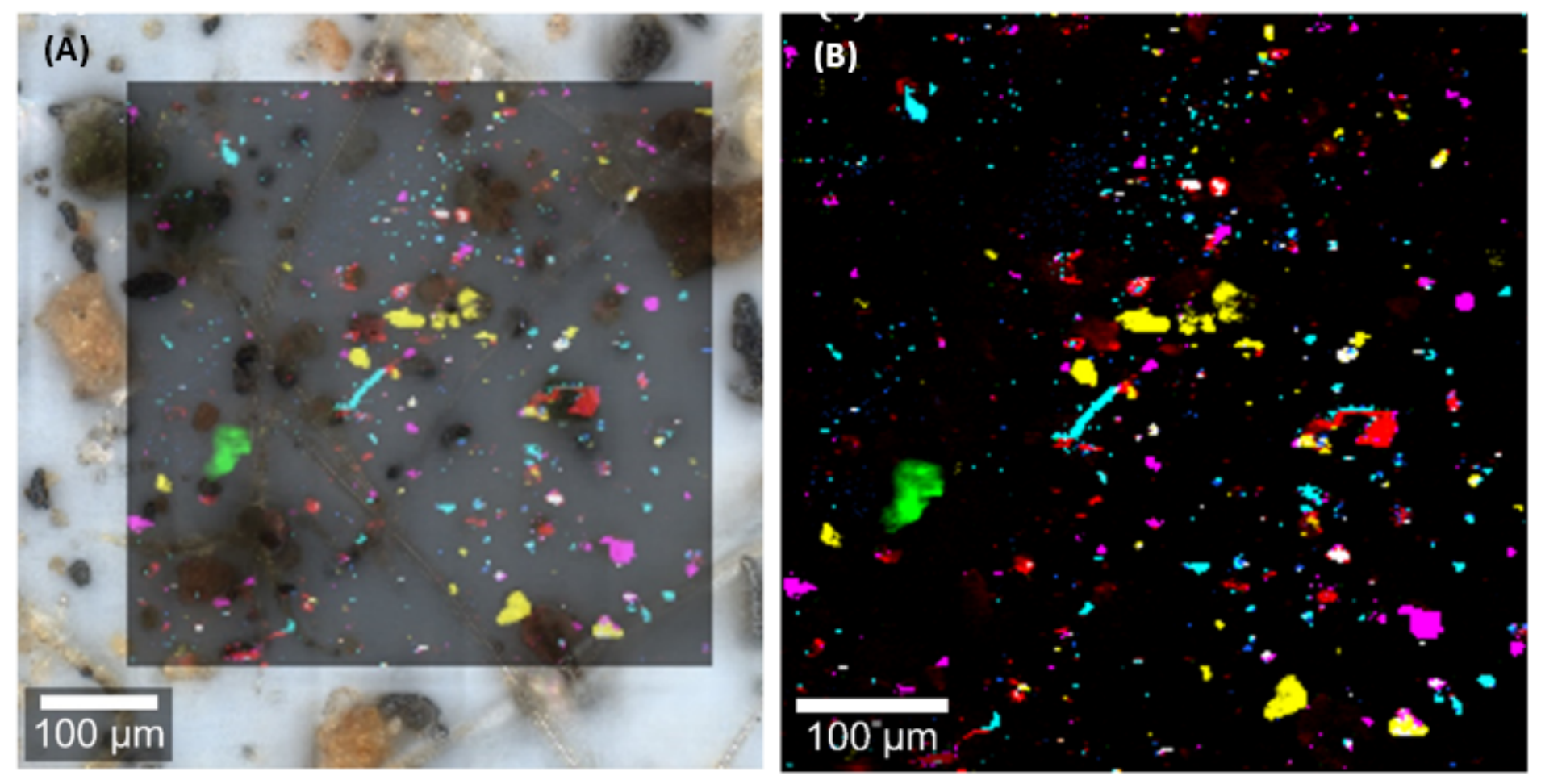

\section{Figure 7}

(A) Overlay of optical microscopy image and component distribution from Raman imaging for the region where the PDMS MP particle was found; (B) component distribution from Raman imaging extracted by True Component Analysis, colour code corresponds to: red - carbon black, blue - titanium dioxide, green - PDMS MP particle, cyan - bacteria, purple - dolomite, and ochre - quartz. Raman spectra of the components are displayed in Supplementary information Fig. S8c

\section{Supplementary Files}

This is a list of supplementary files associated with this preprint. Click to download.

- KernchenetalSIMicropl.Nanopl..docx 